\title{
DIFERENTES RECIPIENTES E SUBSTRATOS NA PRODUÇÃO DE MUDAS DE CAFEEIROS ${ }^{1}$
}

\author{
Containers and substrates in seedlings production of coffee tree
}

\author{
Haroldo Silva Vallone ${ }^{2}$, Rubens José Guimarães ${ }^{3}$, Antônio Nazareno Guimarães Mendes ${ }^{3}$, \\ Carlos Alberto Spaggiari Souza ${ }^{4}$, Rodrigo Luz da Cunha ${ }^{5}$, Fábio Pereira Dias ${ }^{2}$
}

\begin{abstract}
RESUMO
Com o objetivo de avaliar os efeitos de diferentes recipientes e substratos na produção de mudas de cafeeiro (Coffea arabica L.), foi conduzido um experimento no Setor de Cafeicultura da Universidade Federal de Lavras - UFLA, no período de setembro de 2003 a janeiro de 2004. Utilizou-se o delineamento experimental em blocos casualizados, em esquema fatorial $3 \times 3$. Os recipientes utilizados foram tubetes de polietileno rígido com capacidade volumétrica de $50 \mathrm{~mL}$; tubetes de $120 \mathrm{~mL}$; e saquinhos de polietileno, nas dimensões de $20 \mathrm{~cm}$ de altura por $10 \mathrm{~cm}$ de largura e capacidade volumétrica aproximada de $700 \mathrm{~mL}$. Os substratos utilizados foram substrato alternativo (65\% de casca de arroz carbonizada $+35 \%$ de substrato comercial); substrato comercial Plantmax hortaliças HT; e substrato padrão ( $70 \%$ de terra $+30 \%$ de esterco bovino peneirados). Os resultados obtidos permitem concluir que os recipientes e os substratos utilizados influenciam significativamente o desenvolvimento das mudas de cafeeiro, sendo que os recipientes de maior volume (saquinho de polietileno e tubete de $120 \mathrm{~mL}$ ) preenchidos com os substratos alternativo e comercial proporcionam mudas com maior desenvolvimento.
\end{abstract}

Termos para indexação: Tubete, saquinho de polietileno, casca de arroz carbonizada.

\begin{abstract}
With the objective of evaluating the effects of different recipients and substrates on the production of coffee tree seedlings (Coffea arabica L.), an experiment was carried out at the Coffee Sector of the Universidade Federal de Lavras, MG - UFLA, in the period of September 2003 to January 2004. The experiment was arranged in a randomized block design using a 3x3 factorial scheme. The recipients used were rigid polyethylene tubettes $/ 50 \mathrm{~mL}$ capacity; tubettes $/ 120 \mathrm{~mL}$; and $10 x 20 \mathrm{~cm}$ polyethylene bags with approximate capacity of $700 \mathrm{~mL}$. The substrates used were alternative substrate, composed of $65 \%$ charred rice hulls $+35 \%$ commercial substrate; Plantmax $\mathrm{HT}^{\circledR}$; and standard substrate, composed of $70 \%$ soil $+30 \%$ (sieved) cattle manure. The results obtained brought us to the conclusion that the type of recipient and substrate, in fact, significantly influence the development of coffee tree seedlings; and the recipients of larger volume (polyethylene bags and $120 \mathrm{~mL}$ tubettes) filled with alternative and commercial substrates provide seedlings with improved growth rate.
\end{abstract}

Index terms: Tubette, polyethylene bags, charred rice hulls.

(Recebido em 5 de junho de 2006 e aprovado em 6 de março de 2009)

\section{INTRODUÇÃO}

A cafeicultura ocupa um lugar de destaque no agronegócio brasileiro, sendo responsável por uma expressiva importância econômica, tanto interna como externa e social, movimentando, de acordo com CECAFÉ (2006), US $\$ 4,5$ bilhões e gerando mais de 8,5 milhões de empregos diretos e indiretos. O Brasil é o maior produtor mundial de café, responsável por $40 \%$ da produção e, segundo Companhia Nacional de Abastecimento-CONAB (2006), o parque cafeeiro brasileiro é formado por mais de 5,9 bilhões de plantas cultivadas, em 2,4 milhões de hectares. A produção brasileira na safra 2005/2006 foi de 32,94 milhões de sacas de café beneficiado.

Para a exploração comercial de uma cultura perene como o cafeeiro, é necessário o planejamento de todas as fases, particularmente daquelas ligadas diretamente à implantação e formação da lavoura. Qualquer erro cometido nesse período pode comprometer seriamente a exploração, resultando em baixa produtividade e menor longevidade da lavoura (Mendes \& Guimarães, 1998). Em virtude disso, a utilização de mudas de alta qualidade se torna uma etapa decisiva dentro do processo de implantação de uma lavoura

\footnotetext{
${ }^{1}$ Parte da tese apresentada à Universidade Federal de Lavras, pelo primeiro autor, para obtenção do grau de doutor em Agronomia, área de concentração Fitotecnia.

'Instituto Federal de Educação, Ciência e Tecnologia do Triângulo Mineiro Campus Uberaba, MG - Rua João Batista Ribeiro n. 4000 - Bairro Mercês 38.064-790 - Uberaba, MG - haroldo@iftriangulo.edu.br

${ }^{3}$ Universidade Federal de Lavras/UFLA - Departamento de Agricultura - Lavras, MG

${ }^{4}$ CEPLAC - Linhares, ES

${ }^{5}$ EPAMIG/CTSM - Lavras, MG
}

Ciênc. agrotec., Lavras, v. 34, n. 1, p. 55-60, jan./fev., 2010 
cafeeira. Mudas de alta qualidade são aquelas produzidas a baixo custo, que possam se adequar aos atuais sistemas de plantio, além de sobreviverem e se desenvolverem bem após o plantio (Johnson \& Cline, 1991).

Vários fatores exercem influências no desenvolvimento de mudas durante a fase de viveiro, como por exemplo, o tamanho do recipiente e a composição do substrato, entre outros. No caso do cafeeiro (Coffea arabica L.), os tipos de mudas mais comumente utilizados são as produzidas em sacolas de polietileno, utilizando substrato constituído por terra e esterco bovino e as produzidas em tubetes plásticos, de diferentes tamanhos, utilizando substrato comercial. Além disso, vários substratos alternativos, utilizando diversos componentes vêm sendo estudados e recomendados. Estes tipos de mudas podem apresentar comportamentos diferentes quando implantadas no campo, porém, a maioria das pesquisas avalia apenas a fase de produção de mudas, não verificando o comportamento destas, após o plantio no campo. Esse resultado seria de extrema importância para subsidiar a melhor escolha pelos cafeicultores.

O substrato é um insumo importante dentro do sistema de produção de mudas de cafeeiro, sendo responsável por $38 \%$ do custo de produção das mudas, quando se utiliza tubetes de $120 \mathrm{~mL}$, desconsiderando o gasto com a adubação (Guimarães et al., 1998). Atualmente, o substrato mais utilizado para produção em tubetes é constituído de casca de Pinus moída, compostada e enriquecida com nutrientes. A fertilização do substrato tem sido realizada, utilizando fertilizante de liberação lenta.

A granulometria é um atributo físico fundamental à manutenção da integridade do conjunto muda $\mathrm{x}$ substrato e à preservação da sua estabilidade após a retirada do tubete e o manuseio da muda no plantio. Tal fato é desejável, pois as raízes de cafeeiro são pouco lignificadas e, portanto, suscetíveis às rupturas e aos desvios laterais, no momento do plantio (Favarin et al., 2008).

Sabe-se que a forma e o tamanho do recipiente influenciam a dinâmica da movimentação de água nesse pequeno volume. Sendo assim, recipientes com volumes entre 5 e $50 \mathrm{~mL}$ e altura entre 2 e $7 \mathrm{~cm}$, denominados 'plugs', necessitam de substratos com porosidade total acima de $90 \%$ e densidade abaixo de $200 \mathrm{~g} \mathrm{~L}^{-1}$. Os recipientes com volume entre 50 e $500 \mathrm{~mL}$ e altura entre 5 e $15 \mathrm{~cm}$, denominados tubetes, sacos ou vasos, também necessitam de um substrato com porosidade elevada e pouco denso. Por motivo de sanidade, densidade e retenção de água, não se recomenda a utilização de solo mineral nesses recipientes (Kämpf, 2002). De acordo com Verdonck et al. (1983), um substrato para ser considerado ideal deve apresentar as seguintes características físicas: porosidade total inferior a $85 \%$ de seu volume, 20 a $30 \%$ de espaço de aeração, 20 a $30 \%$ de água facilmente disponível e 4 a $10 \%$ de água de reserva. As características químicas mais importantes são o pH, a condutividade elétrica, os teores disponíveis dos nutrientes (Abreu et al., 2002).

A restrição radicular, imposta pelo reduzido volume e pelas paredes dos recipientes, reduz alguns parâmetros importantes na avaliação da qualidade de mudas, como altura, área foliar e produção de biomassa (Townend \& Dickinson, 1995; Leles et al., 1998). Johnson et al. (1996), citados por Samôr et al. (2002), relatam que o pequeno volume dos recipientes proporcionam uma condição de estresse à mudas e, nestes casos, tende a ocorrer aumento de alocação de fotoassimilados para as raízes, em detrimento da parte aérea.

De acordo com Reis et al. (1989), caso haja restrições ao desenvolvimento radicular, a má formação inicial das raízes pode persistir após o plantio, prejudicando o desenvolvimento das plantas no campo.

Vallone (2003), estudando a substituição do substrato comercial por casca de arroz carbonizada, concluiu que o substrato que proporcionou melhor desenvolvimento das mudas de cafeeiro foi constituído por $65 \%$ de seu volume com casca de arroz carbonizada e o restante, $35 \%$ do volume, com substrato comercial. O mesmo autor, avaliando o desenvolvimento de mudas de cafeeiro em tubetes de 50 e $120 \mathrm{~mL}$ de capacidade, observou que as mudas produzidas em tubetes de $120 \mathrm{~mL}$ apresentam maior desenvolvimento em relação às mudas produzidas em tubetes de $50 \mathrm{~mL}$, sem contudo, afetar as relações entre parte aérea e sistema radicular até o terceiro par de folhas verdadeiras. Cunha et al. (2002), estudando a influência de tamanhos de recipientes e tipos de substratos na produção de mudas de cafeeiro em tubetes, utilizaram três tamanhos de recipientes: 50, $120 \mathrm{e}$ $275 \mathrm{~mL}$ e quatro tipos de substrato, sendo um substrato comercial Plantmax e os outros três, constituídos de diferentes proporções de esterco bovino, composto orgânico, terra de subsolo, vermiculita, casca de arroz carbonizada e areia grossa. Observaram que o tubete com $120 \mathrm{~mL}$ de volume e o substrato comercial proporcionaram melhor desenvolvimento às mudas de cafeeiro.

Diante do exposto, neste trabalho, objetivou-se avaliar os efeitos de diferentes recipientes e substratos na produção de mudas de cafeeiro durante a fase de viveiro.

\section{MATERIAL E MÉTODOS}

Este trabalho foi instalado e conduzido no Setor de Cafeicultura do Departamento de Agricultura da Universidade Federal de Lavras - UFLA, localizada no sul 
do Estado de Minas Gerais, com uma altitude média de 910 metros, latitude de $21^{\circ} 14^{\prime} 06^{\prime}$ 'S e longitude de $45^{\circ} 00^{\prime} 00^{\prime}$ ' $\mathrm{W}$. $\mathrm{O}$ experimento foi montado e conduzido no período de setembro de 2003 a janeiro de 2004. O delineamento experimental utilizado foi o de blocos casualizados (DBC) em esquema fatorial $3 \times 3$ (três tipos de recipientes e três substratos), totalizando 9 tratamentos, que foram dispostos em parcelas subdivididas, sendo as parcelas constituídas pelos recipientes e as subparcelas, pelos substratos. Este procedimento foi escolhido para facilitar a montagem da estrutura de produção, uma vez que todas as mudas foram colocadas em uma bancada suspensa e evitar que as mudas produzidas em saquinhos sombreassem as mudas em tubetes. Cada subparcela foi constituída por 42 mudas, sendo as 20 centrais consideradas úteis para os três experimentos, destas 20 , as cinco centrais foram utilizadas para a análise. Os recipientes foram colocados em um canteiro suspenso, a um metro acima do nível do solo, confeccionado com tela de arame ondulado com aberturas quadradas de $1 \frac{1 / 2}{2}$, , arame de $3,5 \mathrm{~mm}$ de diâmetro e com 1,2 $\mathrm{m}$ de largura, para os tubetes. No caso do saquinho de polietileno, foi construída uma bancada de madeira, ao lado e na mesma altura da estrutura destinada aos tubetes. A cobertura do viveiro foi feita com sombrite de cor preta com passagem de $50 \%$ da luminosidade, colocada a dois metros de altura em relação ao solo. As irrigações foram feitas duas vezes ao dia, utilizando sistema de irrigação por microaspersão, procurando fornecer uma lâmina de 4,5 mm de água por dia, de acordo com Guimarães et al. (1998). Os recipientes utilizados foram: a) tubetes de polietileno rígido com capacidade volumétrica de $50 \mathrm{~mL}$, que possui forma cônica, seis estrias internas, $2,7 \mathrm{~cm}$ de diâmetro interno superior, $1,0 \mathrm{~cm}$ de diâmetro interno inferior e altura de $12,2 \mathrm{~cm}$. b) tubetes de polietileno rígido com capacidade volumétrica de $120 \mathrm{~mL}$, possui forma cônica, contendo cinco estrias internas, $3,7 \mathrm{~cm}$ de diâmetro interno da abertura superior, $0,8 \mathrm{~cm}$ de diâmetro interno da abertura inferior e 14 $\mathrm{cm}$ de altura; e c) saquinhos de polietileno, nas dimensões de $20 \mathrm{~cm}$ de altura por $10 \mathrm{~cm}$ de largura $(7 \mathrm{~cm}$ de diâmetro quando preenchido com substrato) e $0,006 \mathrm{~cm}$ de espessura, com 36 furos na metade inferior para drenagem da água e uma capacidade volumétrica aproximada de $700 \mathrm{~mL}$.

Os substratos utilizados nos experimentos foram: a) substrato alternativo, que tem seu volume constituído por $65 \%$ de casca de arroz carbonizada e $35 \%$ de substrato comercial, recomendado por Vallone (2003); b) substrato comercial Plantmax hortaliças $\mathrm{HT}^{\circledR}$, constituído à base de casca de pinus processada e enriquecida, vermiculita e turfa processada e enriquecida, recomendado por Melo (1999); e c) substrato padrão para produção de mudas em sacolas, constituído por $70 \%$ de terra peneirada e $30 \%$ de esterco bovino peneirado, recomendado por Guimarães \& Mendes (1998). Nas Tabelas 1 e 2, são apresentados os resultados das análises químicas e físicas, respectivamente, dos três substratos utilizados nesse experimento, antes de receberem a adubação. As análises foram realizadas pelo Laboratório de Análise de Solo e Planta do Instituto Agronômico de Campinas. Para a adubação dos substratos, utilizou-se o fertilizante de liberação lenta Osmocote, formulação 15-10-10 de NPK acrescido de 3,5\% de Ca, 1,5\%

Tabela 1 - Características químicas dos três substratos supracitados, sem a adição de fertilizantes: $\mathrm{pH}$, condutividade elétrica (CE) e teores solúveis de nutrientes.

\begin{tabular}{|c|c|c|c|c|c|c|c|c|}
\hline \multirow{2}{*}{ Substrato } & \multirow[t]{2}{*}{$\mathrm{pH}$} & $\mathrm{CE}$ & N-Nit. & N-Am. & $\mathrm{P}$ & $\mathrm{K}$ & $\mathrm{Ca}$ & $\mathrm{Mg}$ \\
\hline & & \multicolumn{4}{|c|}{$\mathrm{dS} \mathrm{m}^{-1}$} & \multicolumn{3}{|c|}{$\mathrm{mg} \mathrm{L}^{-1}$} \\
\hline Alternativo & 5,7 & 1,2 & 12,8 & 4,5 & 8,6 & 103,7 & 82,6 & 32,4 \\
\hline Comercial & 5,0 & 2,8 & 46,2 & 7,6 & 10,8 & 119,3 & 178,6 & 85,9 \\
\hline Padrão* & 6,6 & 0,6 & 34,6 & 3,4 & 0,4 & 103,7 & 16,9 & 8,7 \\
\hline \multirow{2}{*}{ Substrato } & $\mathrm{S}$ & $\mathrm{Na}$ & $\mathrm{Cl}^{-}$ & B & $\mathrm{Cu}$ & $\mathrm{Fe}$ & $\mathrm{Mn}$ & $\mathrm{Zn}$ \\
\hline & \multicolumn{8}{|c|}{$\mathrm{mg} \mathrm{L}^{-1}$} \\
\hline Alternativo & 57,5 & 70,0 & 84,1 & 0,1 & 0,04 & 0,6 & 0,4 & 0,1 \\
\hline Comercial & 383,0 & 29,6 & 199,2 & 0,3 & 0,02 & 0,5 & 0,4 & 0,1 \\
\hline Padrão* & 1,3 & 21,6 & 77,0 & 0,1 & 0,01 & 0,05 & 0,02 & $<0,01$ \\
\hline
\end{tabular}

Análise realizada pelo Laboratório de Análise de Solo e Planta do Instituto Agronômico de Campinas.

Método de extração: 1:1,5 (Holanda). Métodos de determinação: N-(amoniacal e nitrato): destilação; K, Ca, Mg, P, S, Cu, Fe, Mn, Zn: ICP-OES.

* Método de extração: 1:2 (Holanda). Métodos de determinação: N-(amoniacal e nitrato): destilação; K, Ca, Mg, P, S, Cu, Fe, Mn, $\mathrm{Zn}$ : ICP-OES. 
de $\mathrm{Mg}, 3,0 \%$ de $\mathrm{S}, 0,02 \%$ de $\mathrm{B}, 0,05 \%$ de $\mathrm{Cu}, 0,5 \%$ de $\mathrm{Fe}$, $0,1 \%$ de Mn, $0,004 \%$ de Mo e $0,05 \%$ de Zn. Foi utilizada a dosagem de $8,3 \mathrm{~kg} \mathrm{~m}^{3}$ de substrato (Melo, 1999). A cultivar utilizada foi a Acaiá Cerrado, MG - 1474. As sementes foram colhidas no campo de produção de sementes do Setor de Cafeicultura da UFLA, semeadas em germinador de areia e cobertas com uma camada de meio centímetro de areia no germinador. A repicagem foi feita quando as plântulas atingiram o estádio de "palito de fósforo".

Tabela 2 - Características físicas dos três substratos supracitados: sólidos (S), porosidade total (P.T.), espaço de aeração (E.A.), água facilmente disponível (A.F.D.) e água retida a $50 \mathrm{~cm}$ de coluna d'água (A.R.50).

\begin{tabular}{cccccc}
\hline Substrato & S. & P. T. & E. A. & A. F. D. & A. R. 50 \\
\cline { 2 - 6 } & \multicolumn{5}{c}{$\%$} \\
\hline Alternativo & 22 & 78 & 38 & 18 & 22 \\
Comercial & 28 & 72 & 9 & 22 & 41 \\
Padrão & 28 & 72 & 8 & 17 & 47 \\
\hline
\end{tabular}

Análise realizada pelo Laboratório de Análise de Solo e Planta do Instituto Agronômico de Campinas.

O experimento foi encerrado quando todos os tratamentos atingiram pelo menos quatro pares de folhas verdadeiras. Foram avaliadas cinco plantas de cada tratamento para as seguintes características: a) Altura das plantas; b) Diâmetro da base do caule; c) Número de nós: Contado a partir da inserção das folhas cotiledonares até a inserção do último par de folhas; d) Área foliar; e) Massa seca do sistema radicular; f) Massa seca da parte aérea e g) Relação massa seca do sistema radicular/massa seca da parte aérea. Foi realizada a análise de variância dos dados à significância de 5\% e 1\% de probabilidade pelo teste $\mathrm{F}$, utilizando-se o programa computacional 'SISVAR', desenvolvido por Ferreira (2000). Quando diferenças significativas foram detectadas, os fatores qualitativos foram agrupados pelo teste de Scott-Knott, aos níveis de $5 \%$ e $1 \%$ de probabilidade, segundo metodologia recomendada por Banzatto \& Kronka (1995).

\section{RESULTADOS E DISCUSSÃO}

O resultado das análises estatísticas indicou que não houve interação entre os fatores, recipientes e substratos, para nenhuma das características avaliadas, indicando que os fatores agem de maneira independente sobre tais características. Esses resultados estão de acordo com Campos (2002) e discordam de Cunha et al. (2002). Esses autores trabalharam com diferentes recipientes e substratos, mas não os mesmos do presente trabalho. Observou-se, neste trabalho, que o comportamento das mudas de cafeeiro nos três substratos utilizados, foi semelhante nos três recipientes estudados.

As médias observadas de diâmetro de caule, altura de mudas, número de nós, área foliar, massa seca da parte aérea, massa seca do sistema radicular e relação massa seca do sistema radicular/massa seca da parte aérea de mudas de cafeeiro em função de diferentes recipientes e substratos são apresentadas nas Tabelas 3 e 4, respectivamente.

Com relação aos efeitos dos recipientes, observouse que as mudas produzidas no recipiente de menor capacidade volumétrica, isto é, o tubete de $50 \mathrm{~mL}$, apresentaram as menores médias para a maioria das características avaliadas, há exceção apenas para massa seca do sistema radicular que não apresentou diferença entre os tratamentos para relação entre as massa secas do sistema radicular e da parte aérea. Esses resultados estão de acordo com Johnson et al. (1996), citados por Samôr et al. (2002), que relatam que mudas, cujos sistemas radiculares se encontram em condições de estresse, tendem aumentar a alocação de fotoassimilados para as raízes, em detrimento da parte aérea. Mesmo se tratando de um volume muito reduzido, a média observada de massa seca do sistema radicular foi semelhante às observadas nos outros recipientes, entretanto, a parte aérea foi inferior aos demais,

Tabela 3 - Valores médios ${ }^{1}$ de diâmetro de caule (Diâm.), Altura de muda (Altura), número de nós ( $\mathrm{N}^{\circ}$ nós), área foliar (A. F.), massa seca da parte aérea (MSPA), massa seca do sistema radicular (MSSR) e relação massa seca do sistema radicular/massa seca da parte aérea (MSSR/MSPA) em mudas de cafeeiro em função de diferentes recipientes.

\begin{tabular}{ccccccccc}
\hline Recipiente & $\begin{array}{c}\text { Diâm. } \\
(\mathrm{mm})\end{array}$ & $\begin{array}{c}\text { Altura } \\
(\mathrm{cm})\end{array}$ & $\mathrm{N}^{\mathrm{o}}$ nós & $\begin{array}{c}\text { A. F. } \\
\left(\mathrm{cm}^{2}\right)\end{array}$ & $\begin{array}{c}\text { MSPA } \\
(\mathrm{g})\end{array}$ & $\begin{array}{c}\text { MSSR } \\
(\mathrm{g})\end{array}$ & $\begin{array}{c}\text { MSSR/ } \\
\text { MSPA }\end{array}$ \\
\hline Tubete $50 \mathrm{~mL}$ & $2,57 \mathrm{~b}$ & $13,60 \mathrm{~b}$ & $4,18 \mathrm{~b}$ & $92,47 \mathrm{c}$ & $0,712 \mathrm{c}$ & $0,245 \mathrm{a}$ & $0,347 \mathrm{a}$ \\
Tubete $120 \mathrm{~mL}$ & $2,82 \mathrm{a}$ & $16,96 \mathrm{a}$ & $4,78 \mathrm{a}$ & $145,84 \mathrm{~b}$ & $0,979 \mathrm{~b}$ & $0,244 \mathrm{a}$ & $0,249 \mathrm{~b}$ \\
Saq. Polietileno & $2,88 \mathrm{a}$ & $16,61 \mathrm{a}$ & $4,95 \mathrm{a}$ & $181,75 \mathrm{a}$ & $1,115 \mathrm{a}$ & $0,237 \mathrm{a}$ & $0,213 \mathrm{~b}$ \\
\hline
\end{tabular}

${ }^{1}$ Médias seguidas pela mesma letra na vertical não diferem entre si, pelo teste de Scott-Knott, ao nível de 5\% de probabilidade. 
Tabela 4 - Valores médios ${ }^{1}$ de sete características de desenvolvimento em mudas de cafeeiro em função de diferentes substratos. UFLA, Lavras, MG, 2006.

\begin{tabular}{cccccccc}
\hline Substrato & $\begin{array}{c}\text { Diâm. } \\
(\mathrm{mm})\end{array}$ & $\begin{array}{c}\text { Altura } \\
(\mathrm{cm})\end{array}$ & $\mathrm{N}^{\circ}$ nós & $\begin{array}{c}\text { A. F. } \\
\left(\mathrm{cm}^{2}\right)\end{array}$ & $\begin{array}{c}\text { MSPA } \\
(\mathrm{g})\end{array}$ & $\begin{array}{c}\text { MSSR } \\
(\mathrm{g})\end{array}$ & $\begin{array}{c}\text { MSSR/ } \\
\text { MSPA }\end{array}$ \\
\hline Alternativo & $2,78 \mathrm{a}$ & $16,21 \mathrm{a}$ & $4,53 \mathrm{a}$ & $153,05 \mathrm{a}$ & $0,999 \mathrm{a}$ & $0,250 \mathrm{a}$ & $0,258 \mathrm{a}$ \\
Comercial & $2,82 \mathrm{a}$ & $16,27 \mathrm{a}$ & $4,63 \mathrm{a}$ & $144,32 \mathrm{a}$ & $0,962 \mathrm{a}$ & $0,253 \mathrm{a}$ & $0,274 \mathrm{a}$ \\
Padrão & $2,66 \mathrm{~b}$ & $14,67 \mathrm{~b}$ & $4,75 \mathrm{a}$ & $122,69 \mathrm{~b}$ & $0,844 \mathrm{~b}$ & $0,223 \mathrm{~b}$ & $0,277 \mathrm{a}$ \\
\hline
\end{tabular}

${ }^{1}$ Médias seguidas pela mesma letra na vertical não diferem entre si, pelo teste de Scott-Knott, ao nível de 5\% de probabilidade.

o que resultou em uma maior relação entre a massa seca do sistema radicular e da parte aérea. Essa característica é citada por Samôr et al. (2002) como indicativa de qualidade de mudas, sendo que quanto maior a relação entre a massa seca do sistema radicular e parte aérea, melhor a qualidade da muda, entretanto, o mesmo autor recomenda não analisar isoladamente esta característica.

Para as características área foliar e massa seca da parte aérea, as melhores médias foram obtidas em mudas produzidas em saquinho de polietileno. As mudas produzidas nesse recipiente também apresentaram média superior, juntamente com as produzidas em tubete de 120 $\mathrm{mL}$ para as características diâmetro de caule, altura de mudas e número de nós. Mudas produzidas nesses dois recipientes também foram semelhantes na relação entre as massas secas do sistema radicular e da parte aérea, sendo, porém, inferiores à média obtida pelo tubete de $50 \mathrm{~mL}$. De modo geral, a maioria dos pesquisadores que trabalham com diferentes tamanhos de recipientes em mudas, não só de cafeeiro, mas também espécies florestais e frutíferas, obtêm melhores médias em recipientes de maiores volumes (Campos, 2002; Cunha et al., 2002; Vallone, 2003; Girardi et al., 2005).

Com relação aos efeitos dos substratos, observouse que apenas para as características número de nós e relação entre as massas secas do sistema radicular e da parte aérea, não foram detectadas diferenças significativas entre as médias. Para as demais características, o substrato alternativo, juntamente com o comercial apresentaram médias superiores às obtidas pelo substrato padrão. Esse resultado pode estar relacionado à fertilidade natural dos substratos, em que o substrato padrão apresenta menores níveis de vários nutrientes (Tabela 1) e também às características físicas dos substratos. Nesse sentido, Kämpf (2002) não recomenda a utilização de solo mineral (principalmente argiloso) em recipientes com menos de 500 $\mathrm{mL}$ de capacidade volumétrica, em razão de motivos sanitários, mas, principalmente, decorrente das características físicas deste, relacionadas à densidade, aeração e retenção de água por este tipo de substrato.
Esses resultados são semelhantes aos obtidos por Vallone (2003), que comparou o mesmo substrato comercial com diferentes proporções de casca de arroz carbonizada, concluindo que o substrato constituído de $65 \%$ de casca de arroz carbonizada $+35 \%$ de substrato comercial Plantmax ${ }^{\circledR}$, trata-se de uma alternativa viável à produção de mudas de cafeeiro em tubetes, necessitando apenas ser testado em condições de campo, após o plantio.

\section{CONCLUSÕES}

Os recipientes de maior volume (saquinho de polietileno e tubete de $120 \mathrm{~mL}$ ) preenchidos com os substratos alternativos (constituído por $65 \%$ de casca de arroz carbonizada e $35 \%$ de substrato comercial plantmax Hortaliças $\mathrm{HT}^{\circledR}$ ) e comercial (plantmax Hortaliças $\mathrm{HT}^{\circledR}$ ) proporcionam mudas com crescimento mais acelerado.

\section{REFERÊNCIAS BIBLIOGRÁFICAS}

ABREU, M.F. de; ABREU, C.A. de; BATAGLIA, O.C. Uso da análise química na avaliação da qualidade de substratos e componentes. In: FURLANI, A.M.C. (Ed.). Caracterização, manejo e qualidade de substratos para produção de plantas. Campinas: Instituto Agronômico, 2002. p.17-28. (Documentos IAC, 70).

BANZATTO, D.A.; KRONKA, S.N. Experimentação agrícola. 3.ed. Jaboticabal: Funep, 1995. 247p.

CAMPOS, K.P. Desenvolvimento de mudas de cafeeiro (Coffea arabica L.) produzidas em diferentes substratos, fertilizações e tamanhos de tubetes. 2002. 90p.

Dissertação (Mestrado em Fitotecnia)-Universidade Federal de Lavras, Lavras, 2002.

CECAFÉ. Produção, comercio e consumo de café. Disponível em: $<$ http://www.cecafe.com.br/cofeedinner >. Acesso em: 19 jan. 2006. 
CONSELHO NACIONAL DE ABASTECIMENTO. $\mathbf{1}^{\mathbf{0}}$ levantamento safra 2006-07. Disponível em: <http:// www.conab.gov.br/download/safra/1/LevantamentoSafra2006-07.pdf). Acesso em: 19 jan. 2006.

CUNHA, R.L. da; SOUZA, C.A.S.; ANDRADE NETO, A. de; MELO, B. de; CORRÊA, J.F. Avaliação de substratos e tamanhos de recipientes na formação de mudas de cafeeiro (Coffea arabica $\mathrm{L}$ ) em tubetes. Ciência e Agrotecnologia, Lavras, v.26, n.1, p.7-12, 2002.

FAVARIN, J.L.; FAVARIN JUNIOR, J.L.; REIS, A.R. dos; CAMARGO, F.T. Metodologia para estimar a estabilidade do conjunto muda x substrato de cafeeiro. Ciência Rural. Santa Maria, v.38, n.1, p.34-38, jan./fev. 2008.

FERREIRA, D.F. Análises estatísticas por meio do Sisvar para Windows versão 4.0. In: REUNIÃO ANUAL DA REGIÃO BRASILEIRA DA SOCIEDADE INTERNACIONAL DE BIOMETRIA, 45., 2000, São Carlos. Anais... São Carlos: UFSCar, 2000. p.255-258.

GIRARDI, E.A.; MOURAO FILHO, F. de A.A.; GRAF, C.C.D.; OLIC, F.B. Vegetative growth of citrus nursery trees related to the container volume. 2005. Disponível em: uwww.edpsciences.org/articles/fruits/pdf/2005/02/, i5011.pdf $>$. Acesso em: 19 jan. 2006.

GUIMARÃES, P.T.G.; ANDRADE NETO, A. de; BELLINI JUNIOR, O.; ADÃO, W.A.; SILVA, E.M. da Produção de mudas de cafeeiros em tubetes. Informe Agropecuário, Belo Horizonte, v.19, n.193, p.98-108, 1998.

GUIMARÃES, R.J.; MENDES, A.N.G. Produção de mudas de cafeeiro. Lavras: UFLA/FAEPE, 1998. 60p.

JOHNSON, J.D.; CLINE, M.L. Seedling quality of southern pines. In: DUREYA, M.L.; DOUGHERTY, P.M. (Eds.). Forest regeneration manual. Doudrecht: Kluwer Academic, 1991. p.143-162.

JOHNSON, J.M. et al. Growth, water relations and solute accumulation in osmotically stressed seedlings of the Colophospermum mopane. Tree Physiology, v.16, p.713718, 1996.
KÄMPF, A.N. O uso de substrato em cultivo protegido no agronegócio brasileiro. In: FURLANI, A.M.C. (Ed.). Caracterização, manejo e qualidade de substratos para produção de plantas. Campinas: Instituto Agronômico, 2002. p.1-6. (Documentos IAC, 70).

LELES, P.S.S.; CARNEIRO, J.G.A.; BARROSO, D.G. Comportamento de mudas de Hymanea courbaril L. var stilbocarpa(Hayne) Lee et Langenh. E Apuleia leiocarpa (Vog.) Macbr, produzidas sob três regimes de irrigação. Revista Árvore, Viçosa, v.22, n.1, p.11-19, 1998.

MELO, B. de Estudos sobre produção de mudas de cafeeiro (Coffea arabica L.) em tubetes. 1999. 65p. Tese (Doutorado em Fitotecnia)-Universidade Federal de Lavras, Lavras, 1999.

MENDES, A.N.G.; GUIMARÃES, R.J. Plantio e formação da lavoura cafeeira. Lavras: UFLA/FAEPE, 1998. 42p.

REIS, G.G.; REIS, M.G.F.; MAESTRI, M.; XAVIER, A.; OLIVEIRA, L.M. Crescimento de Eucayiptus camaldulensis, E. grandis e E. cloeziana sob diferentes níveis de restrição radicular. Revista Árvore, Viçosa, v.13, n.1, p.1-18, 1989.

SAMÔR, O.J.M.; CARNEIRO, J.G. de A.; BARROSO, D.G.; LELES, P.S. dos S. Qualidade de mudas de angico e sesbânia, produzidas em diferentes recipientes e substratos. Revista Árvore, Viçosa, v.26, n.2, p.209-215, 2002.

TOWNEND, J.; DICKINSON, A.L. A comparison of rooting environments in containers of different sizes. Plant and Soil, Champaign, v.175, p.179-146, 1995.

VALLONE, H.S. Produção de mudas de cafeeiro (Coffea arabica L.) em tubetes com polímero hidroretentor, diferentes substratos e adubações. Lavras: UFLA, 2003. $75 \mathrm{p}$.

VERDONCK, O.; PENNINCK, R. de; BOODT, M. de. The physical properties different horticultural substrates. Acta Horticulturae, Amsterdam, v.150, p.155-160, 1983. 